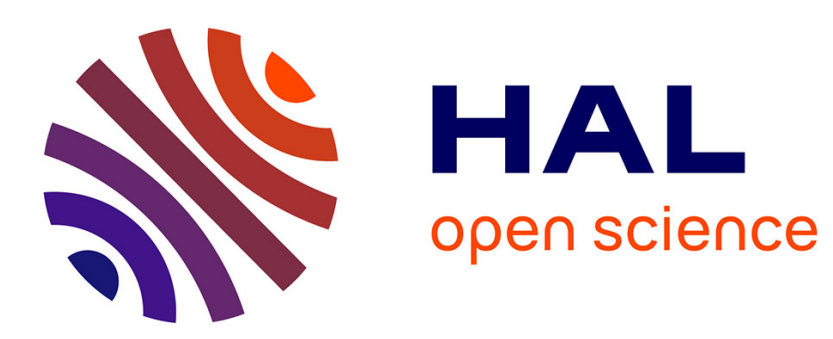

\title{
Temperature and humidity behavior of a Corona based smoke sensor
}

\author{
Z Mokhtari, Stéphane Holé, J Lewiner
}

\section{To cite this version:}

Z Mokhtari, Stéphane Holé, J Lewiner. Temperature and humidity behavior of a Corona based smoke sensor. Journal of Electrostatics, 2015, 76, pp.62-66. 10.1016/j.elstat.2015.05.013 . hal-01166942

\section{HAL Id: hal-01166942 \\ https://hal.sorbonne-universite.fr/hal-01166942}

Submitted on 23 Jun 2015

HAL is a multi-disciplinary open access archive for the deposit and dissemination of scientific research documents, whether they are published or not. The documents may come from teaching and research institutions in France or abroad, or from public or private research centers.
L'archive ouverte pluridisciplinaire HAL, est destinée au dépôt et à la diffusion de documents scientifiques de niveau recherche, publiés ou non, émanant des établissements d'enseignement et de recherche français ou étrangers, des laboratoires publics ou privés. 


\title{
Temperature and humidity behavior of a Corona based smoke sensor
}

\author{
Z. Mokhtari ${ }^{1}$, S. Holé ${ }^{1}$ and J. Lewiner ${ }^{2}$ \\ ${ }^{1}$ LPEM, CNRS UMR8213, PSL Research University, ESPCI-ParisTech, Sorbonne Universités, UPMC Univ Paris 06 \\ ${ }^{2}$ Fonds de l'ESPCI-Georges Charpak \\ 10, Rue Vauquelin, 75005, Paris, France \\ Corresponding author: stephane.hole@espci.fr
}

KEYWORDS: Smoke sensor, Ionic sensor, Corona effect

\begin{abstract}
Ionization smoke sensors are amongst the best smoke sensors; however, the little radioactive source that they include is no longer desirable since recycling gets more complicated. In this paper we discuss an electrostatic system in which corona phenomena is used to generate the ions needed to smoke detection. We show how the velocity of ions is reduced in our system for a better interaction between smoke and drifting ions. Influence of smoke, temperature and moisture is studied. It is shown that the proposed sensor has a good sensitivity compared with conventional ionic and optical smoke sensors.
\end{abstract}

\section{Introduction}

Smoke is one of the first indications of a fire, therefore smoke detection can help to prevent fire progression and save many lives. The alarm of smoke sensors is particularly important in case of nocturnal fires or in case of fires taking place in non-supervised areas, since any delay could lead to dramatic issues. It is known that smoke sensors have a great influence on the number of death [1]. Though 96\% of USA houses are equipped with smoke sensors, $20 \%$ of these are not working and it can be estimated that 1100 lives could be saved every year if all were properly working. There is still one death by fire every 156 minutes in USA. This problem is not restricted to USA as illustrated in Figure 1 which reports the number of death every year per million people in European countries. 


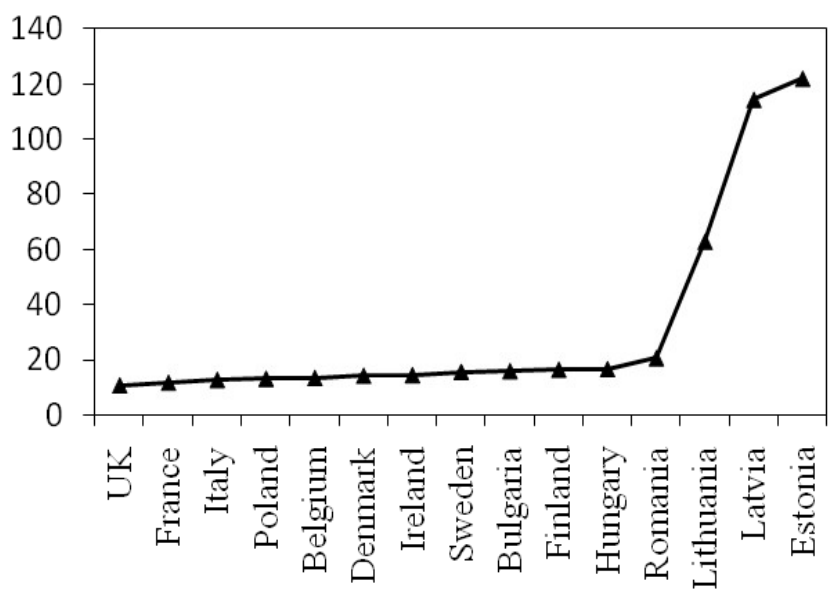

Figure 1: Annual death number in some European countries per million civilians.

There are also statistics showing that most of the industrial accidents are due to fire. In the case of France as shown in Table 1, fire represent 51\% of industrial accidents between 1992 and 2005 [2].

Table 1: Ratio of industrial accidents in France between 1992 and 2005.

\begin{tabular}{|l|l|}
\hline Total accident number & 21765 \\
\hline Fire & $51 \%$ \\
\hline Scattering pollutant & $47 \%$ \\
\hline Explosions & $5,3 \%$ \\
\hline Dominos effects & $3,2 \%$ \\
\hline
\end{tabular}

Research on fire detection is an old story. In the case of domestic smoke sensors, the first truly low cost and easy to use home smoke sensor was invented by Duane D. Pearsall in 1965. He used battery as source of energy, which was easy to install and to replace by the owner. Pearsall Company, Statitrol Corporation, was the first which began the mass production of the home smoke sensors, and the first commercial smoke detectors came to market in 1969 [3].

Nowadays, various physical phenomena are used for detecting fires, so there are different kinds of fire detectors adapted to given places and situations. Usual fire detectors in residential and industrial buildings are smoke detectors which provide sufficiently sensitive detection in the earliest stages of fire propagation.

Among the different kinds of smoke sensors, ionic smoke sensor is one of the best. They are composed of a source of ionization for generating charges and a drift chamber in which charges can slowly drift between electrodes polarized at low voltage. That drift generates a measurable continuous electric current. 
When smoke particles enter the chamber, they attach to the charges, reducing drastically the measured current, which in turn triggers the alarm. That is illustrated in Figure 2. Various geometries and modes of operation have been developped to improve the efficiency of ionic sensors for detecting smoke or aerosols. See for instance Reference [4] in which a judicious combination of optical and ionic detections is used. As well, another kind of ionic interaction has been proposed for detecting smoke [5] in which smoke triggers a discharge instead of cancelling a continuous current.

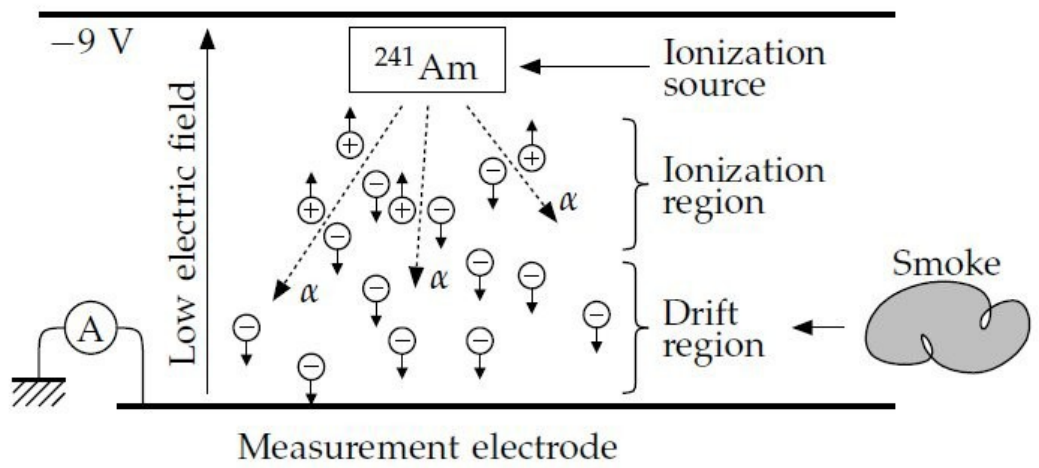

Figure. 2 Principle of ionic smoke sensors. The ion source is made of an americium radioactive element.

Compared to optical smoke sensors, ionic smoke sensors have a very good performance. They respond more quickly to flaming fires. Also they are sensitive to less smoke amount than optical sensors. Moreover ionization sensors have a higher degree of security compared to optical sensors since the alarm intrinsically sounds when the battery starts to fail, warning that it is time to change it before the detector becomes ineffective.

\section{Ion source}

\subsection{Radioactive ion source}

From the first ionic smoke sensors to the last most developed ones, they are all made around of a radioactive source to generate ions. Usually a small quantity of americium-241 (Am-241), about $0.3 \mu$ is used to generate alpha particles in the ionization chamber of the ionic smoke sensor. Alpha particles generate ions in the drift chamber by ionization of air molecules. The drift of these ions under electric field generate a DC current typically of the order of a fraction of nanoamp, in absence of smoke particles. 
Even if this kind of ionic sensor is very efficient, according to new standards they are no longer authorised in almost all of the developed countries because of the radioactive sources they include for generating the ions. Such radioactive sources are indeed difficult to collect and to recycle.

\subsection{Alternative ion source}

Different physical phenomena can be used to generate ions such as field emission [6쁘], thermionic emission [75], and photoelectric emission [의 or discharge phenomena [무]. In this study, we have chosen corona discharge as an alternative ion generation method.

Corona discharge is a phenomenon, which can be used to create charged particles in air. Corona discharge occurs only in highly non-uniform electric fields. A sharp electrode under high voltage produces a very high electric field capable to ionize surrounding air. In front of that electrode, another electrode, usually larger than the first one, collects the generated charges. The voltage required to ionize the molecules of air between the electrodes depends on different parameters such as the ionization energy, the presence of particles, the gas pressure, the distance between the electrodes and their shape. There are numerous studies on corona properties either theoretically or experimentally. R.W. Peek described the necessary conditions to produce a corona discharge [108]. Subsequently many papers have been published describing different methods to model corona discharges in different geometries [119, 1210, $\underline{13} 11]$. They give access for instance to the distribution of charges or electric field between the electrodes as well as voltage threshold. The geometry used in our experiments is a wire-plane geometry. During a corona discharge, the space between the electrodes is divided in two distinct regions: (i) a high field ionization region surrounding the sharper electrode where the ions are created and (ii) a low field drift region occupying the remaining interval.

\section{Proposed sensor}

Though a corona discharge generates a lot of ions, they drift too quickly between the electrodes so they cannot well interact with smoke particles. One solution to this problem is to separate the ionization region from the drift region by a voltage-controlled grid electrode. Though many charged particles could be cap- 
tured by the grid electrode, one part passes through the grid and then drifts gently in a controlled low electric field region, generating the electric current of the order of nanoamps. It is important to emphasize that no signal could be detected without the grid. The grid is therefore of crucial importance.

Considering autonomous smoke sensors, the electric consumption is of prime importance. The generation of high voltage from a $9 \mathrm{~V}$ battery is not of particular complexity with a simple switching supply using a single transistor, a transformer, a diode and a capacitor [14]. The efficiency of such supplies is generally above $\underline{80 \%}$. Considering $3 \mathrm{kV}$ output voltage, $10 \mathrm{nA}$ output current and $80 \%$ efficiency, the consumption of the high voltage supply would be less than $40 \mu \mathrm{W}$. As a consequence and considering only the consumption of the high voltage stage, the sensor autonomy would be of the order or 30 years with a conventional $9 \mathrm{~V}$ battery. The generation of a high voltage is therefore not an issue for autonomous smoke sensors. The structure of the proposed-senser is illustrated in Figure-3.

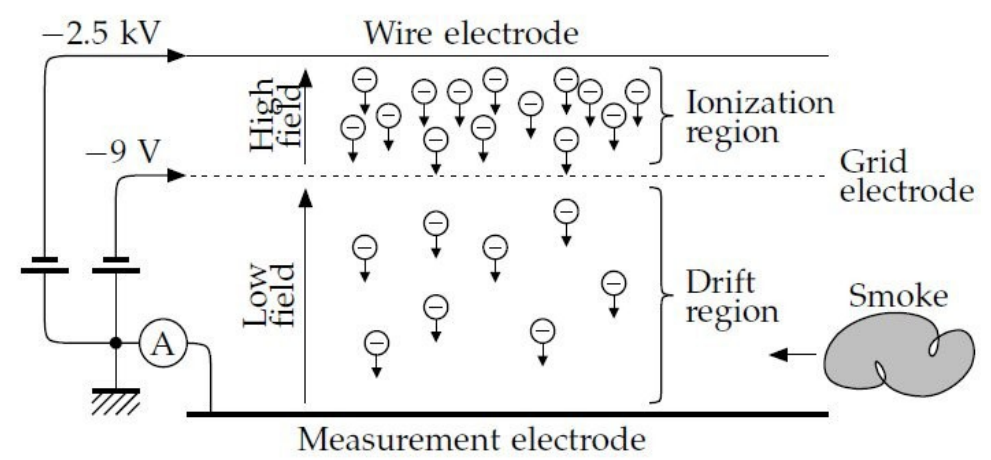

Figure 3: Principle of the proposed sensor. Corona discharge is controlled by a grid electrode.

The structure of the proposed sensor is illustrated in Figure 3. The wire is held to about $-2.5 \mathrm{kV}$ and the grid electrode to $-9 \mathrm{~V}$. The measurement electrode is grounded via a KETHLEY 6487 Picoammeter which can measure electric current down to $10 \mathrm{fA}$, with a maximum error of $0,4 \%$ for the lowest measured current. The electric field in the drift chamber which is delimited by the grid electrode and the measurement electrode is then of the order of $10 \mathrm{~V} / \mathrm{cm}$. The wire is made of gold-coated tungsten and has a diameter of 
either $10 \mu \mathrm{m}$ or $25 \mu \mathrm{m}$ in our experiments. The grid is made of brass wires of 0.3 -mm diameter and 1 -mm pitch.

\section{Measurement protocol}

The proposed sensor is tested in a climatic chamber BINDER APT Line KMF (E5.2). Tests are made at room conditions, at $55^{\circ} \mathrm{C}$ or from $40 \%$ to $90 \%$ moisture.

The sensor is placed near a source of smoke produced by combustion of either Amadou which is a spongy flammable substance prepared from bracket fungi, or a composition of dried flower and straw of Lavander. The smoke granulometry, measured by a particle counter HHPC-6 of Met-One Company, is almost uniform between $0.3 \mu \mathrm{m}$ and $2 \mu \mathrm{m}$ for Amadou and preferentially less than $1 \mu \mathrm{m}$ for lavender straw as shown in Figure 4.

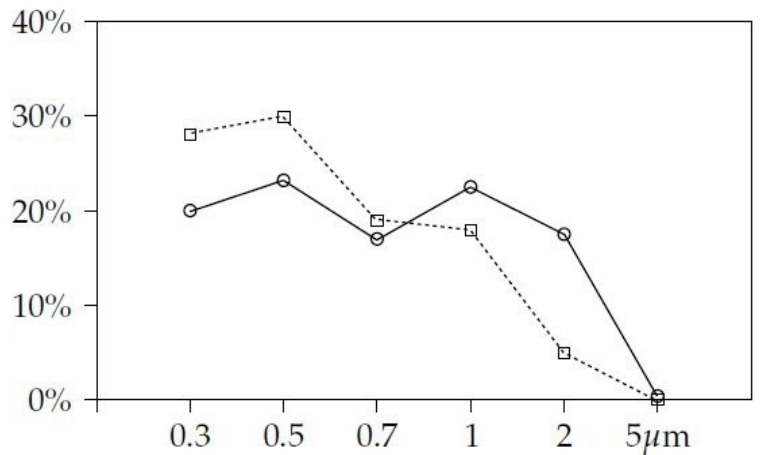

Figure 4: Granulometry of the smoke particles measured by a particle counter HHPC-6.

The voltage applied to the sensor is adjusted as to obtain current of in the range of a fraction of a few nanoamps at the measurement electrode in absence of smoke.

\section{Results and discussion}

\subsection{Geometrical effects}

When smoke enters the drift region of the sensor, the current reduces drastically in amplitude. An example is shown in Figure 5 for the two wire diameters when they are both held to the same high voltage of order of $-2 \mathrm{kV}$. 


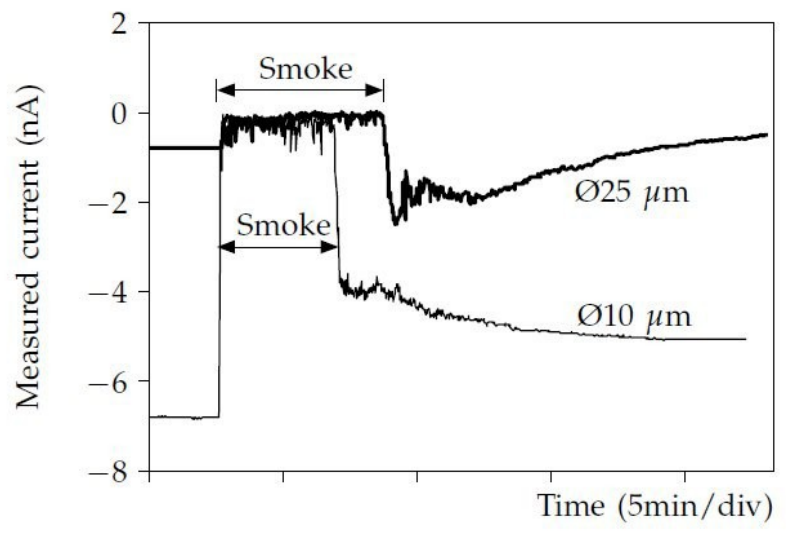

Figure 5: Effect of smoke on the signal for two wire diameters.

The sensitivity is larger for the smaller wire radius. This result can be explained by the effect of the sharpness of wire electrode in corona discharge. As the amplitude of electric field around the wire depends on its sharpness, using a smaller radius wire increases the electric field in air and at the same time the volume of ionization region. Therefore, the number of electrons released in air also increases. As a consequence the measured current increases. In our case the smaller is the wire diameter the better is the sensor sensitivity. Another possibility is to reduce the applied voltage and thus the electric consumption for a given sensitivity.

The distance between the grid electrode and the measurement electrode also alters the sensor sensitivity. Figure 6 shows the influence of two different heights of the chamber.

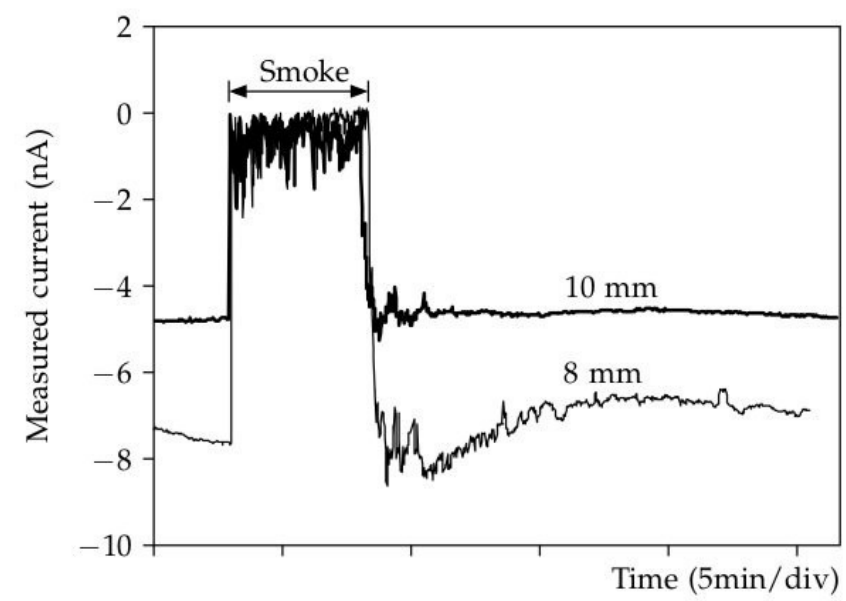

Figure.6: Response of the ionic sensors with different heights of drift chamber. 
As in the case of wire diameter, drift chamber height does not modify the electric current in presence of smoke particles but it affects the current when there is no smoke. One observes that in a drift chamber of 8-mm height, amplitude of electric current in absence of smoke is larger than in a drift chamber of 10-mm height. Reduction of the distance between the grid electrode and the measurement electrode increases the electric current because electrons drift in a larger electric field.

\subsection{Environmental effects}

In order to prevent false alarms it is required that the sensor supports high temperatures and moisture degrees according to the various standards, for instance NF EN 14604. Although sensors are not required to detect smoke at such extreme conditions, they are required to not trigger false alarms.

\section{Effect of temperature}

Figure 7a shows the effect of temperature on the smoke sensor. During the procedure, temperature has been increased up to $55^{\circ} \mathrm{C}$. Then the temperature is maintained with a tolerance of $\pm 2^{\circ} \mathrm{C}$. As observed in the figure, electric current increases with temperature from about $0.1 \mathrm{nA}$ to $0.2 \mathrm{nA}$. When temperature stabilizes, the current also stabilizes at 0,2 nA. This slight increase in the detected current can be explained by the increase in thermal activation energy which helps ionisation at the wire and therefore increases the current. Since smoke produces a large reduction of electric current, the evolution of the current with temperature does not impair sensor detection.

The effect of smoke particles on the current measured by the sensor when it is placed in an environment of $55^{\circ} \mathrm{C}$ is shown on figure $7 \mathrm{~b}$. 

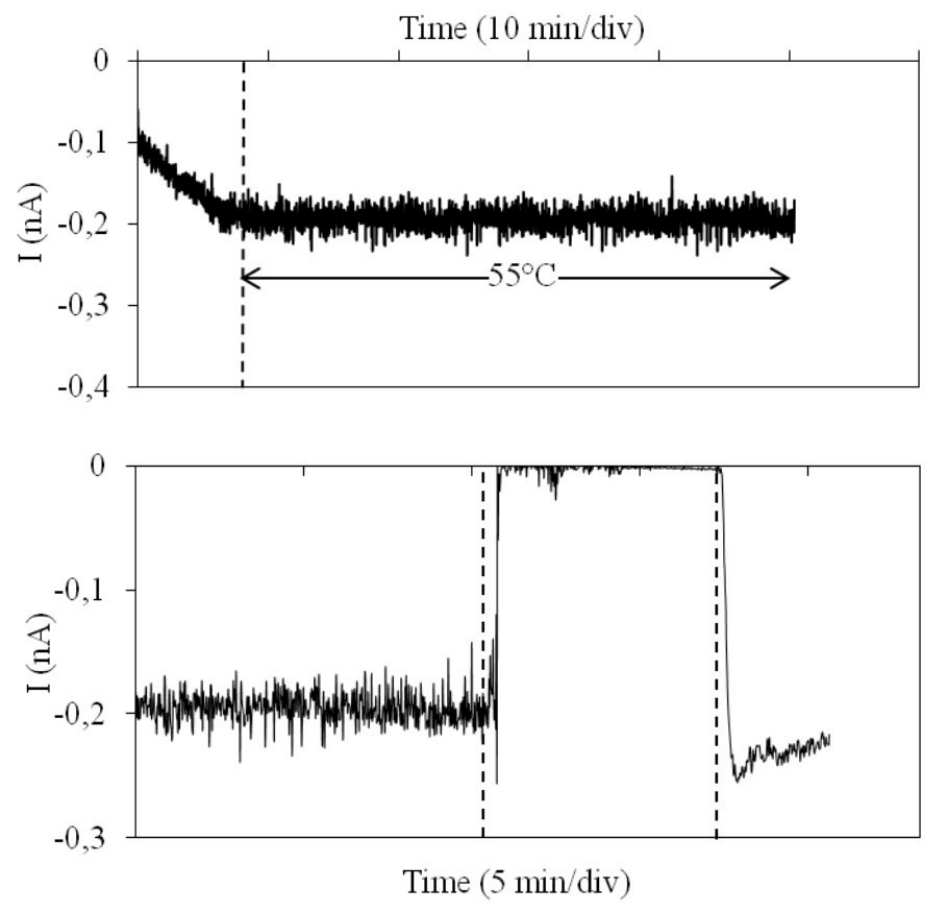

Figure 7: (a) Evolution of response of the ionic sensor with temperature. (b): Evolution of response of the ionic sensor placed at $55^{\circ} \mathrm{C}$ to the smoke particles.

One observes that the electric current decreases immediately and significantly in presence of smoke particles as what happens at room temperature. It can be concluded that temperature is not a significant parameter for our smoke sensor.

\section{Effect of moisture}

Moisture is usually seen as the most impacting parameter for ionic smoke sensors because it modifies ionization thresholds and charge mobilities. Moisture can therefore triggers false alarms. The evolution of the signal without smoke at $40^{\circ} \mathrm{C}$ and under $90 \%$ moisture is presented in Figure 8a. A high relative humidity causes a relatively small decrease of the measured electrical current which does not disturb the sensor. 

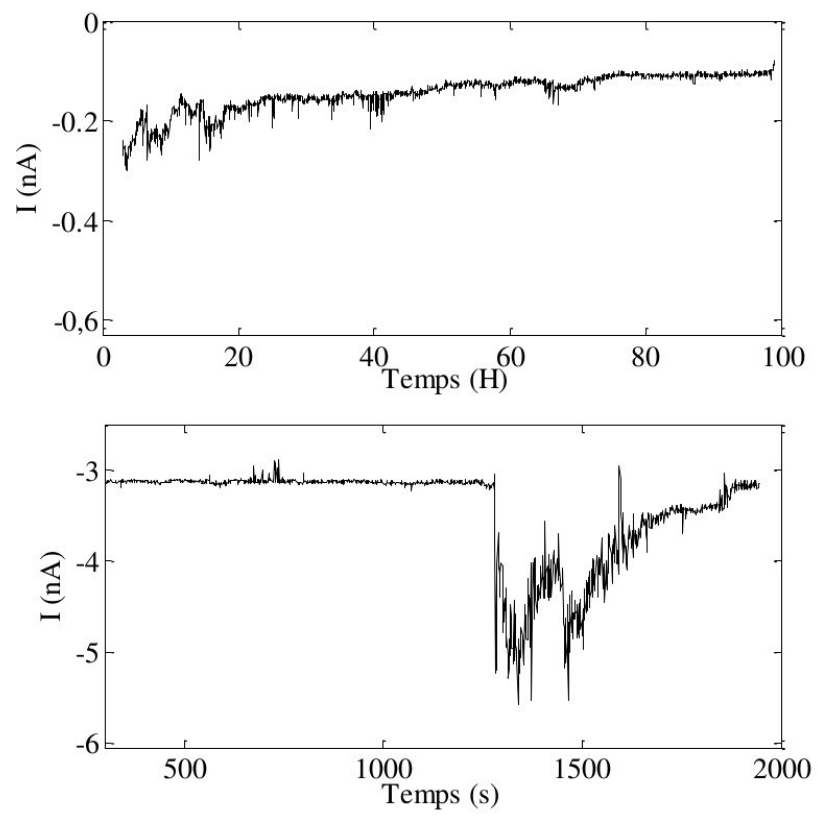

Figure 8: Evolution of response of the ionic sensor under high humidity degree (a), evolution of response of the ionic sensor under high humidity degree in response to smoke (b).

Figure 8b shows the detection of smoke particles by the sensor when exposed to a high humidity degree. One observes that in the case of high humidity, electric current increases in presence of smoke particles contrarily to what happens at room environment.

A hypothesis that may explain this phenomenon is the condensation of humidity on the smoke particles surface in the ionization chamber and creation of heavy particles charged by water molecules or smoke particles ionized near the wire under high voltage. These particles then accelerate in the electric field of the ionization chamber, cannot slow down in the drift chamber due to their high inertia and then arrive on the measuring electrode with still a relatively high speed producing a high current. The interaction with smoke particles in the drift chamber is not sufficiently efficient to obtain the current the formerly observed current drop.

\subsection{Sensor time response}

The efficiency of a smoke sensor depends also on the speed of detection. The response of the proposed sensor is compared with the one of an industrial optical smoke sensor (FINSECUR CAP312A) from which we had a direct access to the sensor digital output. Both sensors are positioned above smoke in a 
similar way. It can be seen in Figure 9 that the optical sensor responds less quickly to smoke than the proposed ionic smoke sensor. The delay is slightly less than a minute which can be a very important delay in case of fire. One part of that delay can be explained by the chicanes used to prevent external light to enter the optical sensor and slow the entrance of smoke at the same time.

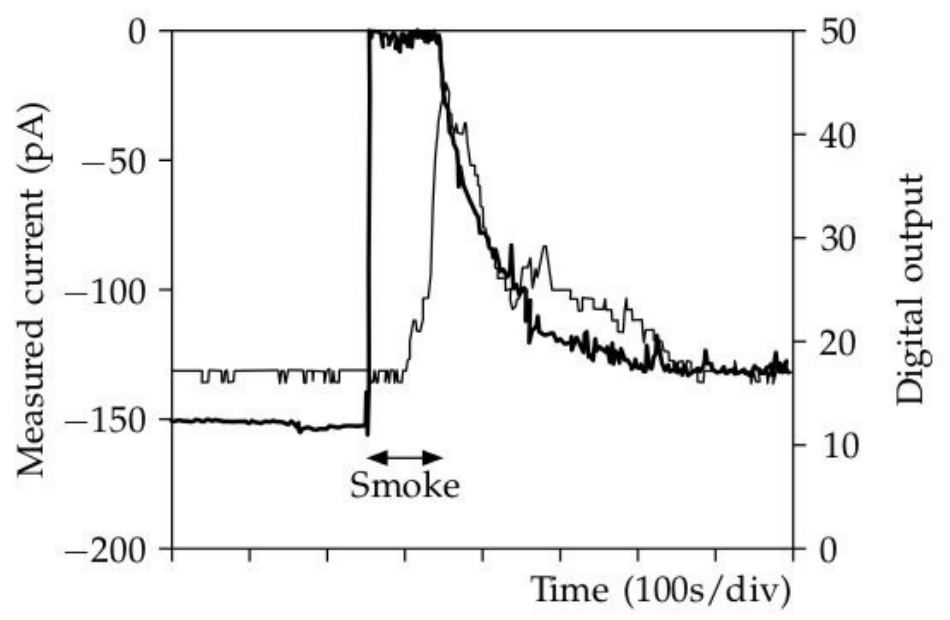

Figure 9: Comparison between the proposed ionic sensor and an industrial optical smoke sensor.

\section{Conclusion}

The radioactive source of conventional ionic sensors has been replaced by a system based on corona discharge generated by a thin wire electrode. A grid electrode under a low voltage is used for slowing the generated charges in the drift region. A repeatable rapid and large signal drop is observed in presence of smoke particles. Also the response delay to the smoke is smaller than the one of industrial optic sensors. Reducing the height of the drift chamber and diameter of the wire electrode, increases the sensitivity of the sensor. So less voltage could be applied to the wire in order to further reduce electric consumption which is here of a few microwatts. Temperature and moisture should not generated false alarms since it either increases the signal, which is the opposite of the smoke effect, or reduces the signal but not as much as the reduction due to smoke particles. With large degree of humidity, the response of the sensor is opposite to the one at low moisture level. However in all cases the presence of smoke produces a very fast and large signal change, so smoke can be detected at any conditions with an appropriate signal processing. 


\section{REFERENCES}

[1] Ahrens M., “US Experience with Smoke Alarms and Other Fire Detection/Alarm Equipment,” NFPA, Quincy, MA, November, 2004.

[2] “Revue Préventique-Sécurité”, No. 88, 2006.

[3] http://www.wpi.edu/Images/Templates/Library/MS 55 Pearsall.PDF, visited in March 2015.

[4] Litton C.D., Smith K.R., Edwards R., and Allen T., " Combined Optical and Ionization Measurement Techniques for Inexpensive Characterization of Micrometer and Submicrometer Aerosols,” Aerosol Science and Technology, vol. 38, pp. 1054-1062, 2004.

\section{5] Mokhtari Z., Holé S. and Lewiner J., "Smoke triggered corona discharge sensor" Journal of}

Electrostatics, vol. 71, pp. 769-772, 2013.

[64] R.H. Fowler, "Electron Emission in Intense Electric Fields”, Proceedings of the Royal Society of London, vol. 119, nº 781, pp. 173-181, 1928.

[75] Richardson Owen, “The emission of positive ions by hot metals”, Wexford College Press, 332 pages, 1921.

[ㅌ] Boutry G. A., "Les phénomènes photoélectriques et leurs applications”, University of Minnesota, Hermann et cie, 1936.

[977] Felici N., “Diélectriques”, Institut Polytechnique, Grenoble, 1966.

[108] Peek F.W., “Dielectric phenomena in H.V. engineering”, Mc Grow Hill, 1929.

[119] P. Atten, K. Adamiak, B. Khaddour, J.-L. Coulomb, "Simulation of corona discharge in configurations with a sharp electrode”, Journal of Optoelectronics and Advanced Materials, vol. 6, pp. 1023-1028, 2004.

[1210] N. Oussalah, Y. Zebboudj, “Negative corona compution in air”, Engineering with Computers, vol. 21, pp. 296-303, 2006.

[1311] M. Arrayas, M.A. Fontelos, J.L. Trueba, “Ionization fronts in negative corona discharges”, Phys. Rev. E, vol. 71, p. 037401, 2005.

\section{[14] Pressman A. “Switching Power Supply Design” (New York: McGraw-Hill), 1998.}

